\title{
Introducción al dossier: "A 20 años del 2001: memorias, representaciones, militancias y reverberancias"
}

\author{
Dossier Introduction: "Twenty Years After 2001: Memories, Representations, \\ Activism, and Reverberations"
}

Introdução ao dossier: "20 Anos do ano 2001: Memórias, representações, militâncias e reverberâncias"

\author{
Ramiro Manduca \\ ramiromanduca@gmail.com \\ Instituto de Investigaciones Gino Germani (IIGG). \\ Universidad de Buenos Aires (UBA), Argentina \\ Maximiliano de la Puente \\ maxidelapuente@gmail.com \\ CONICET, Argentina \\ Instituto de Investigaciones Gino Germani (IIGG). \\ Universidad de Buenos Aires (UBA), Argentina \\ Universidad Nacional de las Artes (UNA), Argentina
}

Cita sugerida: Manduca, R. y de la Puente, M. (2021).

Introducción al dossier: "A 20 años del 2001: memorias,

representaciones, militancias y reverberancias". Aletheia,

12(23), e101. https://doi.org/10.24215/18533701e101

En los estudios sobre el pasado reciente hay una noción, propuesta por el historiador francés Henry Rousso (2012), a la que los/as investigadores/as que nos concentramos en este difuso período acudimos con recurrencia: la de "última catástrofe". Es a partir de este último acontecimiento que, para el autor, se organiza la definición de la historia reciente de cada sociedad, de la historia que puede ser narrada por testigos de esos traumáticos acontecimientos y que aparece como la piedra nodal en la configuración de las memorias sobre 
los mismos. Entendemos que éste es un punto de partida interesante para pensar el 2001, recuperando las huellas que ha dejado en sus protagonistas y en el conjunto del entramado social.

Ese estallido argentino lo entendemos como parte de las rebeliones antineoliberales que, a lo largo de la década de 1990 y comienzos del siglo XXI atravesaron particularmente a América Latina. La noción de "última catástrofe", al calor de esos años y transcurridas dos décadas, parece reconfigurarse como la de "última rebelión". Tras ellas, con mayores o menores grados de contradicciones, ascendieron al poder gobiernos que dieron respuestas favorables a al menos una fracción de las demandas encarnadas por múltiples movimientos sociales que, de manera disruptiva, comenzaron a ocupar las arenas públicas a lo largo y ancho del continente. Los gobiernos "progresistas" supieron incorporarlos a las estructuras estatales, pero, sobre todo, lograron recomponer la legitimidad institucional del estado de derecho. Las memorias sobre esas rebeliones quedaron entonces en disputa entre una posición estatal-progresista que ponderó en ellas los aspectos de la crisis que esa gestión del estado permitió resolver, y aquellas en las que el eje estuvo en el sentido insurreccional, "épico" y novedoso de dichos procesos. Memorias que se disputan entre la crisis y la rebelión, como señaló oportunamente Ezequiel Adamovsky (2016).

Es posible, sin embargo, pensar en un sentido dialéctico estas memorias y por lo tanto también al tándem rebelión/crisis, por ejemplo, en línea con lo planteado por Diego Sztulwark. Para el politólogo argentino la crisis envuelve, en ocasiones, las contradicciones de "develar dispositivos de normalización como opresiones a destituir; y en otras, es la normalidad que muestra hasta qué punto la crisis -el caos y la angustia- es el abismo del que debemos alejarnos como de la lepra" (Sztulwark, 2019, p. 14). Los acontecimientos de los últimos años, nuevamente con epicentro en América Latina, hacen reverberar esa irrupción desestabilizadora de lo dado, esa lucha por la dignidad saboteada. Chile y Colombia, dos países que durante décadas aparecieron como modelos neoliberales triunfantes, surgen ahora, en un sentido benjaminiano, como las "imágenes dialécticas" del 2001.

A 20 años, los acontecimientos de aquel diciembre se encuentran también en tensión, entre su significado estrictamente político y su cristalización como acontecimiento histórico. El 2001 es al mismo tiempo un punto de confluencia de un proceso de mayor alcance iniciado a mediados de la década anterior con las puebladas de Tartagal y Cutral-Co, las irrupciones populares ante las privatizaciones salvajes y la generalización de la pobreza. Un balance ampliamente extendido respecto a los hechos del 2001, tanto en términos políticos como académicos, es que pusieron en crisis los valores propios del sistema político vigente y entre ellos, la eficacia de la democracia representativa. La consigna "Que se vayan todos" (QSVT), abrazada y reproducida por amplios sectores de la sociedad, cristalizó ese sentir que, si bien tuvo su momento de mayor alza durante el verano de 2002, encontró en junio de ese mismo año un punto de clausura con el asesinato de Darío Santillán y Maximiliano Kosteki en la estación Avellaneda. Ese fue, como bien señaló Cecilia Dinerstein, "el momento político clave y simbólico de inflexión en el proceso de apropiación, traducción y posterior integración del QSVT a la hegemonía kirchnerista. Esta masacre concedió la desradicalización y la re-movilización sobre nuevas pautas ya no simplemente del movimiento piquetero, sino del movimiento QSVT en su conjunto" (2016, p. 154).

En esta oportunidad hemos buscado integrar desde una perspectiva interdisciplinaria experiencias colectivas, producciones estéticas y militancias que protagonizaron esos años, conjuntamente con las representaciones o resonancias de este acontecimiento a 20 años de su irrupción. La propuesta de este dossier surge del trabajo que colectivamente emprendimos con el Grupo de Estudios sobre Teatro Contemporáneo, Política y Sociedad en América Latina (IIGG-UBA). Desde este espacio hemos centrado nuestra atención particularmente en las memorias y producciones escénicas que han tenido lugar al calor de la rebelión/crisis, así como en sus "ecos" en producciones contemporáneas. Ante un nuevo aniversario nos parecía relevante poner en diálogo nuestra experiencia con investigaciones en curso desde diversos enfoques, tendientes a actualizar los debates respecto al significado de esta "última rebelión”. Los aportes aquí reunidos cumplen con creces ese objetivo. 
El trabajo de Violeta Nigro Giunta que abre este dossier es un sugerente e innovador aporte que desde la perspectiva de los sound studies logra articular los repertorios sonoros de protesta y la renovación de la escena musical contemporánea en Buenos Aires. En esta singular intersección la autora indaga en los efectos profundos y aún poco estudiados que suscitó en el campo artístico, pero también en el campo perceptual, la crisis del 2001. Para esto reconstruye una genealogía de los sonidos de las protestas. Enhebra desde un instrumento precario como es la cacerola, los sentidos políticos de su uso en las históricas jornadas del 19 y 20 de diciembre al tiempo que reconstruye la proliferación de metáforas sonoras a las que se acudió para definir esa coyuntura. La incorporación de estas sonoridades en obras de música contemporánea de la inmediata poscrisis, la aparición de nuevos modos de organización entre los artistas de este campo e incluso la institucionalización e internacionalización de procedimientos en los que se involucra estas sonoridades urbanas, son aspectos destacados por la autora. El conjunto de los fenómenos abordados pone de relieve los alcances de las memorias sonoras y constituye un aporte fundamental a un campo de estudios sobre una dimensión relegada en las investigaciones del pasado reciente argentino.

En un abordaje que presenta articulaciones similares entre lo popular y lo "culto", puede ubicarse el trabajo de Lola Proaño Gómez. La autora centra su atención en la politicidad de los fenómenos teatrales de los "escenarios cultos" del teatro independiente, en contraposición a las propuestas de los grupos de teatro comunitario, florecientes en los años lindantes al 2001. A pesar de compartir una "atmósfera afectiva" signada por los efectos sociales, políticos y subjetivos del neoliberalismo, la autora identifica dos teatralidades antagónicas. A través del análisis de un corpus de obras de relevantes autores de la escena porteña, como Alejandro Tantanian, Javier Daulte, Rafael Spregelburd y Federico León, entre otros, Proaño Gómez reconoce aspectos distópicos que a su entender son la traducción de la fuerte pregnancia que tuvieron sobre los sectores medios ilustrados, los principios de la filosofía posmoderna y sus tesis devaluadoras del lenguaje. Contrariamente a ese escenario donde primaba la atomización individual y la fragmentación social, en el estudio de las teatralidades comunitarias la autora reconoce procedimientos y modos de organización en los que se reactiva la "función utópica" del quehacer teatral, extensible a otras dimensiones de la vida, para restituir los lazos sociales pretendidamente erosionados por el proyecto neoliberal.

El trabajo de Javier Nuñez, por su parte, es una contribución valiosa para el estudio de las memorias del 2001 en torno a uno de los repertorios de protesta más relevantes: los saqueos. A partir de un trabajo de campo realizado colectivamente en dos barrios del municipio bonaerense de Quilmes, en el que se incluyen entrevistas semi-estructuradas a vecinos que vivían allí al momento del estallido social, el autor indaga en las construcciones memoriales en torno a la figura del "saqueador". A lo largo del artículo se analizan las formas en las que esta figura, que reviste aspectos de ilegalidad, aparece con una común lejanía en la memoria de todas y todos los entrevistados. Las variables sobre las que trabaja Nuñez son las trayectorias laborales y la apropiación del espacio barrial por parte de los vecinos al momento de la crisis. Si bien el autor reconoce un registro heterogéneo respecto a los saqueos, la identificación con los saqueadores persiste como lejana en todos/as los/as entrevistados/as. El saqueador aparece como un "otro", recordable, contextualizable, pero ajeno.

El artículo de Juan Ignacio Vallejos aborda con suma originalidad y pertinencia dos obras de danza contemporánea que remiten a la crisis de 2001. El análisis retoma el concepto de lo intolerable utilizado por el antropólogo Didier Fassin, en relación con otras nociones propias de la teoría política y la teoría de la danza. Vallejos señala que el estallido social de diciembre de 2001 puede pensarse como una experiencia coreográfica colectiva de desidentificación, capaz de habilitar la emergencia histórica de un nuevo sujeto político. En este sentido, realiza un importante aporte para articular los estudios de las artes escénicas, la cultura y la historia política y social.

Con profundidad y gran capacidad de análisis, Marilé Di Filippo examina diversas acciones de activismo artístico en la ciudad de Rosario, en relación a distintos casos de gatillo fácil y violencia institucional, que han tenido lugar en los últimos años. Si bien el trabajo se sitúa desde una perspectiva histórica, que le permite 
vincular los acontecimientos actuales con los ciclos previos de protesta social, en los cuales la crisis de 2001 ocupó un lugar central, indaga a la vez en las continuidades y discontinuidades de los repertorios activistas a partir del cambio abrupto de coyuntura dado por la irrupción de la pandemia del Covid-19.

Por último, incluimos una entrevista al politólogo y activista Diego Sztulwart realizada por ambos coordinadores, en la que indagamos sobre las persistencias del 2001 en el escenario político actual, recuperando para ello la experiencia singular de investigación militante protagonizada por el Colectivo Situaciones y profundizando sobre las reflexiones del autor en su último libro "La Ofensiva Sensible" (2019).

Esperamos que el conjunto de los trabajos aquí reunidos sean un aporte y un disparador para nuevas discusiones y elaboraciones sobre un momento trascendental de nuestra historia reciente.

\section{REFERENCIAS}

Adamovsky, E. (2016). Epílogo. En Ozarow, D; Levey, C y Wylde, C. (Eds.) De la crisis de 2001 al kirchnerismo: Cambios y continuidades (pp. 293-300). Buenos Aires: Prometeo.

Dinerstein, C. (2016). Desacuerdo y esperanza: dos cuestiones veladas por la recuperación de la política de la Argentina post crisis 2001. En Ozarow, D; Levey, C y Wylde, C. (Eds.) De la crisis de 2001 al kirchnerismo: Cambios y continuidades (pp. 151-174). Buenos Aires: Prometeo.

Rousso, H. (2012). La derniére catastrophe. L'historire, le présent, le contemporain. París: Gallimard.

Sztulwark, D. (2019). La ofensiva sensible: neoliberalismo, populismo y el reverso de lo político. Buenos Aires: Caja Negra. 